\title{
Pulmonary Hypertension Following Cardiac Surgery in Children with Down Syndrome: A Review
}

\author{
Abubakar Umar ${ }^{1,}$, Abdullahi A. A. ${ }^{2}$ \\ ${ }^{1}$ Cardiothoracic Surgery Unit, Department of Surgery, Usmanu Danfodiyo University/Usmanu Danfodiyo University Teaching Hospital, \\ Sokoto, Nigeria \\ ${ }^{2}$ Department of Anaesthesiology and Intensive Care, Usmanu Danfodiyo University/Usmanu Danfodiyo University Teaching Hospital, \\ Sokoto, Nigeria \\ Email address: \\ drzuru@yahoo.com (A. Umar) \\ ${ }^{*}$ Corresponding author
}

\section{To cite this article:}

Abubakar Umar, Abdullahi A. A. Pulmonary Hypertension Following Cardiac Surgery in Children with Down Syndrome: A Review. International Journal of Cardiovascular and Thoracic Surgery. Vol. 5, No. 2, 2018, pp. 26-30. doi: 10.11648/j.ijcts.20190502.11

Received: December 13, 2018; Accepted: January 10, 2019; Published: May 20, 2018

\begin{abstract}
Pulmonary hypertension is a known complication in children with congenital heart lesions especially those with left-to-right shunts. Children with Down syndrome are known to have certain types of congenital heart lesions like atrioventricular septal defect, ventricular septal defect, patent ductus arteriosus etc. These lesions can cause pulmonary hypertension if left untreated in any child. In those with Down syndrome, pulmonary hypertension is said to be worse. Several factors have been identified. These factors are upper airway obstruction that is common in all children with this syndrome, abnormality in their pulmonary vascular bed, lower levels of nitric oxide production which is a known vasodilator, abnormalities in their immune system which predisposes them to respiratory tract infection, gastroesophageal reflux disease and recently pulmonary hemosiderosis has been reported. Therefore, children with Down syndrome being prepared for cardiac surgery should be thoroughly evaluated and if possible measures should be taken to minimize untoward effects of these factors.
\end{abstract}

Keywords: Pulmonary Hypertension, Down Syndrome, Cardiac Surgery

\section{Introduction}

Pulmonary hypertension is defined as a mean pulmonary arterial pressure greater than $25 \mathrm{mmHg}$ at rest, with a normal pulmonary artery wedge pressure less than $15 \mathrm{mmHg}$ and an increased pulmonary vascular resistance greater than 3 Wood units $\times \mathrm{M}^{2}$ [1-2]. Pulmonary arterial hypertension is also referenced as a ratio of pulmonary arterial pressure to systemic in excess of 0.5 [3]. Down syndrome is the most common chromosomal abnormality that is characterized by various congenital defects, organic disorders, dysmorphic features and other health-related problems [4]. Congenital heart disease is said to occur in $40-60 \%$ of patients with this chromosomal abnormality. The most common congenital heart disease is complete atrioventricular septal defect. Other congenital heart lesions that can occur are ventricular septal defect, atrial septal defect and tetralogy of Fallot [5]. Pulmonary hypertension is said to be a common complication of patients with Down syndrome and congenital heart disease undergoing cardiac surgery [6]. This increases the rate of pulmonary complications and increase length of hospital stay. The aim of this review is to look at all the factors that are responsible for the development of pulmonary hypertension in this group of patients

\section{Historical Perspective}

The first physician to describe pulmonary vascular sclerosis in an autopsy in 1891 is Ernst von Romberg. There were several reports of death as a result of right heart failure in 1940 from pulmonary hypertension when right catheterization was introduced. Andre Counard and Dickson Richards expanded on the diagnostic procedures in pulmonary hypertension [7].

In 1951 Dresdale tested the acute effect of tolzoline on a young woman with idiopathic pulmonary hypertension and it was said to cause a reduced in pulmonary vascular resistance 
without affecting the systemic effects. Aminore-induced pulmonary hypertension was first noticed in 1960. In 1973 there was an epidemic of aminorex-induced pulmonary hypertension which prompted a detailed research into this disease by World Health Organization. First efficacious treatment of pulmonary hypertension became available in 1995 [8].

\section{Factors That Contribute to Pulmonary Hypertension in Children with Down Syndrome}

\subsection{Congenital Heart Disease with Left to Right Shunt}

The commonest congenital heart disease in children with down syndrome is atrioventricular septal defect which is a form of left to right shunt. This form of defect is known to cause pulmonary hypertension at an early age of life [9]. Other are atrial septal defect, ventricular septal defect and patent ductus arteriosus. In these group of lesions there is increase in pulmonary blood flow. This leads to the development of pulmonary vascular occlusive disease which is supposed to be a protective mechanism against increase pulmonary blood flow but unfortunately its detrimental and irreversible at a stage. Patients with Down syndrome with left to right lesion have the tendency to develop pulmonary hypertension which may manifest in the postoperative period [10].

\subsection{Chronic Upper Airway Obstruction}

Upper airway obstruction is common in Down syndrome due to midfacial hypoplasia, Macroglossia, narrowing of the nasopharynx, tonsillar and adenoidal enlargement, lingual tonsils, Choanal stenosis, shortening of the palate, subglottic stenosis, laryngomalacia, tracheomalacia and congenital malformations of the larynx and trachea. These anatomical abnormalities along with generalized hypotonia, an immature immune system, and a tendency to obesity predispose children with Down syndrome to upper airway obstruction [11-13]. This in conjunction with other factors may contribute to the worsening of pulmonary hypertension and postoperative respiratory complications in children with Down syndrome.

\subsection{Pulmonary Vascular Bed}

Abnormal vasculature of pulmonary bed has been reported in patients with down syndrome. Chi et al reported results of cardiac catheterization in children with Down syndrome and congenital heart diseases with pulmonary hypertension and concluded that children with congenital heart disease and Down syndrome have an unusually high pulmonary vascular resistance and a propensity for early development of severe damage to the pulmonary vascular bed [14]. Thinner pulmonary arterioles have been reported in children with Down syndrome. This has been implicated in the cause of pulmonary hypertension in Down syndrome patients [15].
Pulmonary vein stenosis in these group of patients has not been spared. Gowda et al reported 3 cases of pulmonary vein stenosis causing pulmonary hypertension in children with Down syndrome and advocated thorough evaluation of any child with Down syndrome presenting with progressive pulmonary hypertension to undergo cardiac catheterization to assess haemodynamics and to exclude pulmonary vein stenosis [16]. Autopsies of lung tissues of these children also revealed damage to lung tissue which has also been implicated [17].

\subsection{Effects of Pulmonary Vasodilators}

Nitric oxide which causes pulmonary vasodilatation has been found to be low in children with Down syndrome and pulmonary hypertension. Asymmetric dimethylarginine (ADMA) has been shown to be high in patients with down syndrome. ADMA is said to contribute in lowering the levels of NO production [18-19].

An imbalance in the biosynthesis of thromboxane $A_{2}$ and prostacyclin has been postulated to contribute in early development of pulmonary hypertension in Down syndrome patients. The authors concluded that the predominant biosynthesis of thromboxane $\mathrm{A}_{2}$ over Prostacyclin leading to vasoconstriction was noticed in Down syndrome patients irrespective of whether there is pulmonary hypertension or not. This imbalance therefore, is said to account for rapid progression of pulmonary vascular obstructive disease in infants with Down syndrome [20].

\subsection{Increased Susceptibility to Infections}

This has been linked to abnormalities in the immune system [21-23]. The following factors contribute to susceptibility to infection: mild to moderate reduction in $\mathrm{T}$ cell count, mild to moderate reduction in B cell count, absence of normal lymphocyte expansion in infancy, thymus size is smaller than age-matched control, suboptimal antibody response to immunization, decreased total and specific immunoglobulin $A$ in saliva and decreased neutrophil chemotaxis [24].

\subsection{Gastroesophageal Reflux}

This is said to cause reflux of gastric content into the airway thereby causing lung inflammation and bronchospasm in the upper airway. This will cause an increase in the incidence of lower respiratory tract infection in these patients. Hypotonia seen in Down syndrome patients is associated with poor pharyngeal muscle tone and increase risk of aspiration [25].

\subsection{Pulmonary Hemosiderosis}

Pulmonary hemosiderosis is a rare lung disease characterized by the triad of hemoptysis, iron deficiency anaemia, alveolar and/or interstitial opacities on lung imaging. It is said to be rare in children. Alimi et al looked at the relationship between pulmonary hemosiderosis and Down syndrome in RespRare* network and reported for the first 
time a higher risk of pulmonary hemosiderosis in Down syndrome patients and suggested a chest X-ray in all Down syndrome patients with unexplained anaemia and/or chronic unexplained dyspnea [26].

\section{Treatment}

Pulmonary hypertension before cardiac surgery is associated with increased morbidity and mortality [27-28]. Therefore, the presence of pulmonary hypertension before surgery or appearing during surgery or after will have an impact on survival via its effect on right ventricular function. The following basic principles should be adhered to in order to prevent pulmonary hypertension crisis.

1. Optimization of fluid balance. It is important to avoid excessive fluid in patients with distended inferior vena cava and right ventricle

2. Optimization of metabolic state - correct acidosis, hypoxaemia and anemia

3. Treat respiratory failure. This may entail intubation and use of lung protective ventilation strategies (tidal volume of $6 \mathrm{~mL} / \mathrm{kg}$ and plateau pressure of $<30 \mathrm{cmH}_{2} \mathrm{O}$ and also to optimize oxygenation

4. Maintain systemic perfusion pressure. The mean systolic pressure should be greater than mean pulmonary pressure and if need be pressors should be added

5. Optimization of cardiac output with the aid of ionotropes to maintain normal cardiac index

6. Reduction of right ventricular afterload. It is important to avoid systemic vasodilators. Use of pulmonary vasodilators is recommended. Inhaled vasodilators are less likely to have adverse effect on systemic blood pressure or oxygenation. One can consider combination of inhaled and intravenous.

\subsection{Drugs Commonly Used in Postoperative Patients}

a) Phosphodiesterase-5 inhibitors $\left(\mathrm{PDE}_{5}\right)-$ most widely used in clinical practice in the treatment of pulmonary hypertension in congenital heart disease. Sildenafil is safe and effective [29-30].

b) Endothelin receptor antagonist - Bosentan is said to be efficacious especially in patients with Essenmenger's syndrome. Currently there is little evidence on the use of this drug in pulmonary hypertension in congenital heart diseases [31-32].

c) Nitric oxide - intraoperative nitric oxide inhalation has shown promising result and now routinely used in many institutions in patients that are likely to develop pulmonary hypertension [33].

To date there is no randomized trial on the efficacy of any of the drugs in patients with Down syndrome and congenital heart disease. Some authors have suggested that Bosentan is safe and tolerated in adults Down syndrome patients with congenital heart diseases and pulmonary hypertension [34-35]

\subsection{Newer Therapies}

Cyclosporine is known to inhibit the release of IL-2 as such been shown to cause regression in the degree of pulmonary artery remodeling, pulmonary hypertension and right ventricular hypertrophy in animal models.Antiinflammatory and TNF-a inhibitors agents like Etanercept have been shown to cause reverse remodeling and improvement in haemodynamics in preclinical models. Substances that inhibit apoptosis like survivin has been shown to cause reverse remodeling in pulmonary hypertension [36]. Tacrolimus, an immunosuppressant and Fasudil, a Rho-kinase inhibitor has all shown promising results [37].

\subsubsection{Pulmonary Artery Denervation}

It is a form of transcatheter procedure performed in patients with pulmonary hypertension that do not respond to medical treatment. It has been noticed that increased neurohumoral activation increases catecholamine secretion which in turn causes high sympathetic activity. This forms the basis for pulmonary artery denervation [38].

\subsubsection{Blade-Balloon Atrial Septostomy}

This procedure is considered as a palliative measure in children with PAH who have recurrent syncope, right ventricular failure or chest pain despite maximal medical therapy. This allows right to left shunt at atrial level particularly during pulmonary hypertension crisis. It has also been described as a bridge to recovery or to transplantation [39].

\subsubsection{Pott's Shunt}

It is also a palliative procedure that can be performed in patients with supra-systemic pressure. It entails creating a shunt between left pulmonary artery and descending thoracic aorta. It is recommended before the deterioration of right ventricular function. It decreases right ventricular afterload thereby improving ejection fraction and functional class [40].

\subsubsection{Mechanical Support and Lung Transplantation}

Patients with pulmonary hypertension may be candidates for mechanical respiratory support and lung transplantation. Right ventricular assist devices and extracorporial membrane oxygenation (ECMO) have been used in these patients [41].

\section{Conclusion}

Congenital heart lesions with left-to-right shunt if left untreated can predispose children to pulmonary hypertension. Those with Down syndrome are said to develop the worst form of pulmonary hypertension which has been attributed to several factors that are inherent in children with Down syndrome. It is therefore pertinent to thoroughly evaluate these children in a bid to identify these factors and institute measures to reduce the untoward effects of pulmonary hypertension. 


\section{References}

[1] Hoeper MM, Bogaard HJ, Condliffe R, et al. Definitions and diagnosis of pulmonary hypertension. J Am Coll Cardiol. 2013;62: D42-D50.

[2] Ivy DD, Abman SH, Barst RJ, et al. Pediatric pulmonary hypertension. J Am Coll Cardiol. 2013;62: D117-D126.

[3] Ivy DD. Pulmonary hypertension in children. Cardiol clin. 2016;(34(3): 451-471.

[4] Toth R, Szantos P, Lex DJ, Sapi E, Szatmari A, Gal J, Szantos T, Szekely A. down syndrome and postoperative complications after paediatric cardiac surgery: A propensitymatched analysis. Interactive CardioVascular and Thoracic Surgery. $20131-7$.

[5] Anaclerio S, Di Ciommo V, Michielon G, et al. Conotruncal heart defects: impact of genetic syndromes on immediate operative mortality. Ital Heart J. 2004; 5:624-8.

[6] Calderon-Colmenero J, Flores A, Ramirez S, Patino-Bahena E, Zabal C, Garcia-Montes JA et al. Surgical treatment results of congenital heart defects in children with Down's syndrome. Arch Cardiol Mex 2004;74: 39-44.

[7] Newman JH. Pulmonary hypertension. Am J Respir Crit Care Med 2005;172:1072-7.

[8] Anderson RJ, Malhotra A, Kim NH. Pulmonary hypertension: the evolution of pulmonary hypertension and chronic thromboembolic pulmonary hypertension.J thorac Dis. 2016;8(7):562-565.

[9] Berger TJ, Blackstone EH, Kirklin JW. Survival and probability of cure without and with surgery in complete atrioventricular canal. Ann Thorac Surg. 1979;27:104-111

[10] Kumar KR. Left to right shunt with pulmonary vascular disease still an enigma. Heart Asia. 2015; 7(2): 38-39

[11] Jacobs I, Gray RT, odd W. Upper airway obstruction in children with Down syndrome. Arch Otolaryngol Head Neck Surg.1996;122:945-950.

[12] Mitchell RB, Call E, Kelly J. diagnosis and therapy for airway obstruction in children with Down syndrome. Arch Otolaryngol Head Neck Surg. 2003;129(6):642-645.

[13] Chi TPL, Krovetz J (1975) The Pulmonary Vascular bed in Children with Down syndrome. J Pediatr 86: 533-538.

[14] Banjar H (2009) Down's Syndrome and Pulmonary Arterial Hypertension. PVRI Review 1: 213-2.

[15] Gowda S, Bhat D, Feng Z, Chang CH, Ross RD. Pulmonary vein stenosis with Down syndrome: a rare and frequently fatal cause of pulmonary hypertension in infants and children. Congenital heart dis 2014;9(3):E90-7.

[16] Byard RW (2007) Forensic issues in Down syndrome fatalities. J Forensic Leg Med 14: 475-481.

[17] Holm T, Aukrust P, Aagaard E, Ueland T, Haugstad TS, Kjekshus J, Simonsen S, Froland SS, Gullestad L, Andreassen AK (2002) Hypertension in relation to nitric oxide, asymmetric dimethylarginine, and inflammation: different patterns in heart transplant recipients and individuals with essential hypertension. Transplantation
74:1395-1400.

[18] Kielstein JT, Bode-Boger SM, Hesse G, MartensLobenhoffer J, Takacs A, Fliser D, Hoeper MM (2005) Asymmetrical dimethylarginine in idiopathic pulmonary arterial hypertension. Arterioscler Thromb Vasc Biol $25: 1414-1418$

[19] Fukushima H, Kosaki K, Sato R, Yagihashi T, Gatayama R, Kodo K, Hayashi T, Nakazawa M, Tsuchihashi T, Maeda J, Kojima Y, Yamagishi H, Takahashi T (2010) Mechanisms underlying early development of pulmonary vascular obstructive disease in Down syndrome: an imbalance in biosynthesis of thromboxane $\mathrm{A}(2)$ and prostacyclin. Am J Med Genet A 152A(8):1919-1924.

[20] Burgio GR, Ugazio AG, Nespoli L, Marcioni AF, Bottelli AM, Pasquali F. Derangements of immunoglobulin levels, phytohemagglutinin responsiveness and $\mathrm{T}$ and $\mathrm{B}$ cell markers in Down's syndrome at different ages. Eur J Immunol. 1975;5:600-3.

[21] Cruz NV, Mahmoud SA, Chen H, Lowery-Nordberg M, Berlin K, Bahna SL. Follow up study of immune defects in patients with dysmorphic disorders. Ann Allergy Asthma Immunol. 2009;102:426-31.

[22] Burgio GR, Ugazio AG, Nespoli L, Marcioni AF, Bottelli AM, Pasquali F. Derangements of immunoglobulin levels, phytohemagglutinin responsiveness and $\mathrm{T}$ and $\mathrm{B}$ cell markers in Down's syndrome at different ages. Eur J Immunol. 1975;5:600-3.

[23] Ram G, Chinen J. infections and immunodeficiency in Down syndrome. Clin Exp Immunol. 2011;164(1):9-16.

[24] Thompson L, McElhinney D, Jue K, Hodge D. Gastroesophageal reflux after re- pair of atrioventricular septal defect in infants with trisomy 21: a comparison of medical and surgical therapy. J Pediatr Surg. 1999;34:1359-1363.

[25] Alimi A, Taytard J, Abou Taam R, Houdouin V, Forgeron A et al. Pulmonary hemosiderosis in children with Down syndrome: a national experience. Ophanet Journal of Rare Diseases. 2018;60(13);1-8.

[26] Malouf JF, Enriquez-Sarano M, Pellikka PA, et al. Severe pulmonary hypertension in patients with severe aortic valve stenosis: clinical profile and prognostic implications. J Am Coll Cardiol 2002; 40(4): 789-95.

[27] Tuman KJ, McCarthy RJ, March RJ, Najafi H, Ivankovich AD. Morbidity and duration of ICU stay after cardiac surgery. A model for preoperative risk assessment. Chest 1992; 102(1): 36-44.

[28] Garg N, Sharma MK, Sinha N. Role of oral sildenafil in severe pulmonary arterial hypertension: clinical efficacy and dose response relationship. Int $J$ Cardiol. 2007;120:306-313.

[29] Mukhopadhyay S, Nathani S, Yusuf J, Shrimal D, Tyagi S. Clinical efficacy of phosphodiesterase-5 inhibitor tadalafil in Eisenmenger syndrome-a randomized, placebocontrolled, double-blind crossover study. Congenit Heart Dis. 2011;6:424 - 431

[30] Chau EMC, Fan KYY, Chow WH. Effects of chronic sildenafil in patients with Eisenmenger syndrome versus idiopathic pulmonary arterial hypertension. Int $\mathrm{J}$ Cardiol. 2007;120:301-305. 
[31] Hoeper MM, Bogaard HJ, Condliffe R, Frantz R, Khanna D, Kurzyna M, Langleben D, Manes A, Satoh T, Torres F, Wilkins MR, Badesch DB. Definitions and diagnosis of pulmonary hypertension. J Am Coll Cardiol. 2013;62:D42D50.

[32] D'Alto M, Romeo E, Argiento P, D'Andrea A, Sarubbi B, Correra A, Scognamiglio G, Papa S, Bossone E, Calabro` R, Vizza CD, Russo MG. Therapy for pulmonary arterial hypertension due to congenital heart disease and Down's syndrome. Int J Cardiol. 2013;164:323-326.

[33] Journois D, Pouard P, Mauriat P, Malhere T, Vouhe P, Safran D. Inhaled nitric oxide as a therapy for pulmonary hypertension after operations for congenital heart defects. J Thorac Cardiovasc Surg. 1994;107:1129-35.

[34] Duffels MGJ, Vis JC, van Loon RLE, Nieuwkerk PT, van Dijk APJ, Hoendermis ES, de Bruin-Bon RHACM, Bouma BJ, Bresser P, Berger RMF, Mulder BJM. Effect of bosentan on exercise capacity and quality of life in adults with pulmonary arterial hypertension associated with congenital heart disease with and without Down's syndrome. Am J Cardiol. 2009;103:1309 - 1315 .

[35] Gurtu V, Michelakis ED. Emerging therapies and future directions in pulmonary arterial hyperten- sion. Can J Cardiol. 2015;31(4):489-501.
[36] Reitz BA, Wallwork JL, Hunt SA, et al. Heart- lung transplantation: successful therapy for patients with pulmonary vascular disease. N Engl J Med 1982;306:557-64.

[37] Spiekerkoetter E. FK506 activates BMPR2, rescues endothelial dysfunction, and reverses pulmonary hypertension. J Clin Investig. 2013;123(8):3600-13, Doe Z, et al. Evidence for Rho-kinase activation in patients with pulmonary arterial hypertension. Circ J. 2009;73(9):1731-9.

[38] Chen SL, et al. Hemodynamic, functional, and clinical responses to pulmonary artery denervation in patients with pulmonary arterial hypertension of different causes: phase II results from the pul- monary artery denervation-1 study. Circ Cardiovasc Interv. 2015;8(11).

[39] Chiu JS, et al. Balloon atrial septostomy in pul- monary arterial hypertension: effect on survival and associated outcomes. J Heart Lung Transplant. 2015;34(3):376-80.

[40] Baruteau AE, et al. Potts shunt in children with idiopathic pulmonary arterial hypertension: long-term results. Ann Thorac Surg. 2012;94(3): 817-24.

[41] Kirkby S, Hayes D. Pediatric lung transplantation: indications and outcomes. J Thorac Dis. 2014;6(8):1024-31. 